\title{
The Meeting of East and West
}

\author{
Stephen K. Levine, Ph.D. \\ The European Graduate School, Switzerland
}

CAET is proud to introduce the following series of articles from representatives of the South Asian and Pacific region, most of whose authors belong to ANZACATA (The Australian, New Zealand and Asian Creative Arts Therapies Association). The mandate of our journal is to present perspectives on the arts in education and therapy from both East and West, focusing on China and its neighbors. The introductory piece by Ronald P.M.H. Lay, a North American art therapist and educator who is based in Singapore, raises significant issues about the kind of cross-cultural encounter that our journal wishes to foster.

What does it mean for the East and West to encounter each other? We have to keep in mind the long history of interactions between both parts of the world, beginning with individual Western explorers and missionaries, continuing through the prolonged colonial period of oppression and domination, and now coming to a point of putative equality. We are meeting each other as if for the first time and asking, "Who are you?"-a question which immediately leads to the further ones, "Who am I?" and "Who are we?"

We are, I hope, past the time of exotica, one in which the West put its own fantasies onto its image of Eastern countries, either seeing them as backward and underdeveloped, or positing them as containing "ancient wisdom," but in either case always looking at them from our own perspective. What would it be like to really see the other without superimposing our images on them?And can we see the other seeing us, in our mad rush for accumulation and profit? To what extent have they joined us in what we call, as if it were inevitable, "modernity"?

Encounter does not necessarily mean identity, an attempt to find a universal humanity to which we belong. Neither does it have to lead to reify differences, to assert our radical otherness. That would mean, as Kipling put it, "Oh, East is East, and West is West, and never the twain shall meet."Jean-Luc Nancy, in his book, Being Singular Plural, tries to understand encounter in terms of "nearness." In a genuine relationship the two parties are neither the same nor different; rather we are near to each other, touching but not merging, taking and giving at the same time.

Must the East become like the West, allowing Western models to dominate its own culture, as the main tendencies in Chinese economic and political life seem to assert? Or must those in the West who are looking for alternatives to mindless striving have to become Taoists, Buddhists, Hari Krishna adepts dressed in robes, chanting continually to ward off spiritual discontent?

And what, specifically, of the arts therapies? Should Eastern countries adopt Western arts therapeutic models in order to become professionalized? Or should those of us in the West reject these models, which often seem to take the life out of our work, in order to become more like our fantasies of the other? 
And of course, the basic question remains, what shall we do with our categories of "East" and "West"? Do these abstractions even mean anything in the current world? Does "East" include India and China, two countries with vastly different histories and cultures? Are Italy and the United States the same?And what ofJames Hillman's notion that we should stop turning to the East to find a spiritual ground for our rootlessness, and instead develop a "Southern" psychology, one grounded in sensuality and pleasure?

We are tempted to throw up our hands and see the whole project of bringing East and West together as futile. And yet this "useless passion" (as Sartre called human existence itself) is what we have, perhaps what we are. We cannot avoid it, if we are to come to terms with the world in which we live. Perhaps our way (our Tao?) is to patiently explore the similarities and differences, to choose what we want to give and what we need to take. Our difficult nearness, though resisting facile definition, can actually be seen as a gift, a path rather than a conclusion. This may indeed be true not only for the arts in therapy and education but for all aspects of our cultural life. I see our task in CAET as dwelling in the differences and similarities, keeping ourselves near the other, and finding new forms for our work and life. If we can do this, our differences may actually bring us together.

As Maurice Sendak said in Where the Wild Things Are, "Let the wild rumpus start!" And then, perhaps, "...the walls will become the world all around." 